\title{
ACESSIBILIDADE EM INTERFACES: PESQUISA DE INTERAÇÃO EM UM AMBIENTE VIRTUAL DE APRENDIZAGEM BILÍNGUE (LIBRAS/PORTUGUÊS)
}

\section{ACCESSIBILITY IN INTERFACES: INTERACTION RESEARCH IN A VIRTUAL BILINGUAL LEARNING ENVIRONMENT (LIBRAS/PORTUGUESE)}

\author{
Daniel Henrique Scandolara ${ }^{1}$, E.Pr. \\ Laíse Milo Moraes², M.Rs. \\ Fabiana Paula Bubniak ${ }^{3}$, M.Sc. \\ Bruno Penerai Velloso ${ }^{4}$, D.Sc. \\ Saionara Figueiredo ${ }^{5}$, M.Sc.
}

(1) Instituto Federal de Educação, Ciência e Tecnologia de Santa Catarina (IFSC)

e-mail: daniel.scandolara@ifsc.edu.br

(2) Instituto Federal de Educação, Ciência e Tecnologia de Santa Catarina (IFSC)

e-mail: laise.moraes@ifsc.edu.br

(3) Instituto Federal de Educação, Ciência e Tecnologia de Santa Catarina (IFSC)

e-mail:fabiana.bubniak@ifsc.edu.br

(4) Instituto Federal de Educação, Ciência e Tecnologia de Santa Catarina (IFSC)

e-mail:bruno.velloso@ifsc.edu.br

(5) Instituto Federal de Educação, Ciência e Tecnologia de Santa Catarina (IFSC)

e-mail: saionara.figueiredo@ifsc.edu.br

Palavras-chave: ambiente virtual, acessibilidade, surdos

\begin{abstract}
A cada ano percebe-se o aumento com as preocupações acerca das questões de acessibilidade em interfaces digitais, seja para incluir pessoas com desabilidades ou prover acesso a um número maior de pessoas a esses ambientes. O Ambiente Virtual de Aprendizagem Moodle do Campus Palhoça Bilíngue - IFSC, no que se refere ao ensino e comunicação amplia a possibilidade de aprendizagem e inclusão, principalmente dos surdos. No entanto, os ambientes de aprendizagem e também aqui a página inicial do Moodle carecem de adaptações para ampliar a acessibilidade. Desta forma o objetivo é apresentar o objeto em seu estado da arte e em decorrência do estudo através da lente de Eric Zimmerman, uma das possíveis alternativas para ampliar a acessibilidade do público Bilíngue (Libras/Português), respeitando suas diferenças. A mudança realizada na página foi à troca de estilo de cursos em lista, para uma página de cursos em formato visual.
\end{abstract}




\section{$16^{\circ}$ \\ ERGODESIGN USIHC CINAHPA}

$16^{\circ}$ Ergodesign - Congresso Internacional de Ergonomia e Usabilidade de Interfaces Humano Tecnológica: Produto, Informações Ambientes Construídos e Transporte

$16^{\circ}$ USIHC - Congresso Internacional de Ergonomia e Usabilidade de Interfaces Humano Computador

CINAHPA | 2017 - Congresso Internacional de Ambientes Hipermídia para Aprendizagem.

Key-words: virtual environment, accessibility, deaf

Each year we see the increase with concerns about accessibility issues in digital interfaces, whether to include people with disabilities or to provide access to more people to these environments. The Virtual Environment Moodle Learning Campus Palhoça Bilingue - IFSC, with regard to teaching and communication increases the possibility of learning and inclusion, particularly the deaf. However, learning environments and here too the Moodle homepage require adaptations to broaden accessibility. Thus the goal as to present the object in this state of the art and as a result of the study by lens of the Eric Zimmerman, one of the possible alternatives to expand the accessibility of public Bilingual (Libras/Portuguese), respecting their differences. The change made on the page was the exchange of list courses, to a page of courses in visual format.

\section{Introdução}

Alguns desafios são encontrados ao trabalhar com pessoas surdas pela questão da barreira linguística enfrentada por estes indivíduos. A partir das experiências de trabalho em uma instituição de ensino bilíngue (Libras/Português), um dos desafios emergentes é a falta de acessibilidade em interfaces como: materiais didáticos, sites, televisão, aplicativos para celulares, entre outros. Sabe-se que para esses sujeitos surdos, a língua de sinais é imprescindível para sua comunicação e contato com o mundo, então, um dos problemas aqui levantados é a falta de acessibilidade nas interfaces, justamente pela falta do uso da língua de sinais, a primeira língua da pessoa surda. Esse fenômeno ocorre, em demasia, pelo desconhecimento da cultura surda e também da realidade desses sujeitos, faltando assim, orientações consistentes e projetos para adaptação de interfaces para esse público.

Além das dificuldades acerca da língua de sinais, os ambientes de aprendizagem disponíveis na maioria das instituições de ensino, são de baixo custo e constituídos sobre a perspectiva "software livre" como é o caso do Moodle (Modular ObjectOriented Dynamic Learning Environment) e muitos desses não estão adaptados para pessoas surdas. Ambientes desenvolvidos sobre esta perspectiva são bem recebidos pelas instituições, mas fazem-se necessárias adaptações para que atendam as demandas de acessibilidade, como revela pesquisas de (FAJARDO; VIGO; SALMERÓN, 2009; PEVETA et., 2013).

Diante dessa problemática, o objetivo deste trabalho é apresentar e avaliar parte de uma página inicial de cursos do ambiente virtual de ensino aprendizagem Moodle do Instituto Federal de Santa Catarina - Campus Palhoça Bilíngue, através da lente de Eric Zimmerman considerando-se 4 (quatro) modos de interação. Leva-se aqui em consideração o perfil do público surdo, por meio de um ensaio de interação. Pretende-se avaliar ainda, o nível de satisfação do surdo em relação à interface adaptada se comparada a original.

Este artigo está dividido em oito seções. A seção um apresenta a introdução, a subseção um ponto um descreve a cultura surda e as tecnologias. A subseção um ponto dois explica o designe de usabilidade e interação, a subseção um ponto três aborda acessibilidade web. A subseção um ponto quatro explica o Moodle Campus Palhoça bilíngue e trabalhos relacionados. A subseção um ponto cinco aborda recomendações para interfaces acessíveis. A seção dois descreve a revisão sistemática, a três discorre sobre o objeto de análise. A seção quatro aborda sobre o método. A seção cinco a apresentação e discussão dos resultados. Por fim, são apresentadas as considerações finais acerca do trabalho desenvolvido e as referências utilizadas.

\subsection{Cultura surda e as tecnologias}

Através da linguagem, dos juízos de valor, arte e das motivações é que a cultura surda é expressa, agregando ordem a um determinado grupo, com códigos próprios, formas de organização e solidariedade. Os elementos culturais de qualquer grupo constituem-se da mediação simbólica que torna possível a vida em comum desses sujeitos, além de agregar e recriar novas culturas em função da diversidade de indivíduos que estão inseridos
Realização:

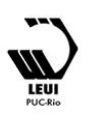




\section{$16^{\circ}$ \\ ERGODESIGN USIHC CINAHPA}

$16^{\circ}$ Ergodesign - Congresso Internacional de Ergonomia e Usabilidade de Interfaces Humano Tecnológica: Produto, Informações Ambientes Construídos e Transporte

$16^{\circ}$ USIHC - Congresso Internacional de Ergonomia e Usabilidade de Interfaces Humano Computador

CINAHPA | 2017 - Congresso Internacional de Ambientes Hipermídia para Aprendizagem. nesse meio. Os surdos são um grupo minoritário que está lutando para que sua cultura seja incluída, no contexto social, como legítima (SÁ, 2006).

A língua de sinais durante muitos anos foi proibida aos sujeitos surdos por ser considerada um meio de comunicação inferior, agressiva e destituída do meio científico. A partir das pesquisas de Stokoe (1960), a língua de sinais passou a ser vista realmente como língua e não apenas como mero gesto. Gesser (2009) explana, as línguas de sinais possuem as mesmas características das línguas orais, como possibilidade de utilização de metáforas, piadas, polissemia, etc. A língua de sinais difere da língua oral, devido sua modalidade visual-espacial, sendo percebida através da visão e produzida através das mãos e das expressões faciais e corporais. Enquanto as línguas orais, como o Português caracterizam-se pela forma oralauditiva.

O termo bilinguismo, no caso do sujeito surdo, é a utilização da sua língua materna a Língua Brasileira de Sinais (LIBRAS) como primeira língua e o Português como segunda língua e na modalidade escrita. Assim, a filosofia bilíngue procura empoderar o sujeito surdo, que não busca adequar-se a realidade ouvinte, usuária de língua oral, mas assume a surdez como parte de sua identidade e característica. Entretanto, ao longo dos anos, as comunidades surdas foram isoladas e fechadas, muito, pelas barreiras da distância ou de acessos aos meios de comunicação mais tradicionais utilizados pela grande massa ouvinte. Com o avanço das tecnologias da informação e comunicação (TIC's), que possibilitam uma abrangência muito maior de usuários e também com o objetivo de promover a troca de informação e comunicação, a população com perda auditiva encontrou uma nova forma de comunicação (MORAES, L. M.; BUBNIAK, F. P.; VELLOSO, B. P.; KAMINSKI, D., 2014). Logo o uso das mídias digitais, como câmeras, vídeos, bate-papos com webcams e inúmeros aplicativo de mensagem através de texto, a comunicação entre usuários da língua de sinais ampliou-se consideravelmente, assim também como a difusão e o reconhecimento dessa língua.
As interfaces para as pessoas surdas podem ser explanadas e projetadas a partir de recursos visuais, não apenas focando nos vídeos em libras, mas sim em elementos visuais que podem ser utilizados como estratégias de acuidade visual. No entanto, a grande parte das interfaces atuais, não é desenvolvida para as pessoas surdas, ou seja, são desenvolvidas de forma empírica, e muitas vezes sem a presença do usuário surdo, implicando em problemas de barreiras de acessibilidade e refletindo no nível de experiência e baixo engajamento dos sujeitos surdos aos quais os projetos são desenvolvidos.

\subsection{Design de usabilidade e interação}

As TIC's estão facilitando a vida dos usuários surdos, justamente por cada vez mais preocuparem-se com a interface e usabilidade. Entretanto com relação ao contexto linguístico a demanda dos usuários surdos é relativamente nova na área de Interação Humano Computador (HCI) em que o conceito é tratado de forma interdisciplinar procurando entender como as pessoas usam as TIC's. Acerca disso, a página do Ambiente Virtual Moodle (AVM) necessita de adaptações para que o usuário surdo possa ter acesso às disciplinas de uma forma mais simplificada. Através desse estudo o autor busca melhorar a eficácia e satisfação dos usuários.

Na área de HCI recomendações e pesquisas são adotadas para o estudo de usabilidade com o intuito de facilitar o acesso e navegação em um site ou sistema. Entretanto o uso dessa prática nem sempre é contextualizada de forma correta, justamente pela preocupação com a experiência interativa que o usuário tem, mas não pensando nos casos específicos de cada indivíduo. Em grande parte, por este motivo, muitos profissionais realizam pesquisas e adaptações próprias em sistemas implementados ou a implementar. No que tange o desenvolvimento de interfaces, deve-se priorizar os objetivos do produto e considerar as necessidades dos usuários. Para atender a esse quesito, técnicas de projeto e avaliação de usabilidade são adotadas com a intenção de promover interações agradáveis e fáceis, criando, portanto, mecanismos capazes de minimizar 


\section{$16^{\circ}$ \\ ERGODESIGN USIHC CINAHPA}

$16^{\circ}$ Ergodesign - Congresso Internacional de Ergonomia e Usabilidade de Interfaces Humano Tecnológica: Produto, Informações Ambientes Construídos e Transporte

$16^{\circ}$ USIHC - Congresso Internacional de Ergonomia e Usabilidade de Interfaces Humano Computador

CINAHPA | 2017 - Congresso Internacional de Ambientes Hipermídia para Aprendizagem. sobrecargas cognitivas ao aliar aspectos do design gráfico e de estética à usabilidade.

Para Preece, Rogers e Sharp (2005, p. 28), projetar uma interação "significa criar experiências que melhorem e entendam a maneira como as pessoas trabalham, se comunicam e interagem. (...) Nesse sentido, consiste em encontrar maneiras de fornecer suporte às pessoas". Com o uso da interação, partiu-se da escolha do texto Eric Zimmerman, Narrativa, Interatividade, Play e Games: Quatro conceitos impertinentes em necessidade de disciplina, para dar suporte à análise de interatividade da página principal do AVM.

\subsection{Acessibilidade web}

O conceito de acessibilidade web está na universalidade, ou seja, nas possibilidades de qualquer usuário, que utilize um agente, seja software ou hardware, de entender, perceber, navegar e interagir com o conteúdo de um site (THATCHER et al., 2002). A acessibilidade dos recursos disponibilizados na web é uma premissa fundamental para a inclusão na sociedade atual. No entanto, um estudo realizado em 2012 pela instituição W3C.br/NIC.br aponta que somente $2 \%$ das páginas web governamentais atualmente são acessíveis (W3CGT, 2012). Neste propósito, é fundamental se referir à Web Accessibility Initiative (WAI) do World Wide Web Consortium (W3C). A Web Accessibility Initiative (WAI) tem como proposta apresentar diretrizes e recomendações para prover acesso e oportunidades igualitárias às pessoas, considerando os diversos tipos de desabilidades.

As proposições da WAI são consideradas referências quando discussões sobre acessibilidade Web são levantadas (WAI, 2012). Visando auxiliar aos autores e desenvolvedores de conteúdo na produção de material acessível às pessoas com deficiência, a WAI articulou a elaboração da Web Content Accessibility Guidelines (WCAG), que se encontra na versão 2.0. O documento é organizado em termos de diretrizes e critérios de sucesso, sendo este último à referência para a definição do nível de conformidade de um website em relação à acessibilidade. Segundo o WCAG 2.0 (2006), as diretrizes e critérios de sucesso de acessibilidade foram construídos com base em quatro princípios básicos: perceptível, operável, compreensível e robusto. Porém, em relação ao WCAG, Kelly et al (2007) apontam que embora o documento seja impecável em sua forma, é demasiadamente genérico, funcionando bem apenas para contextos mais simples. De acordo com os pesquisadores, em contextos que exigem análise e interpretação, as diretrizes deixam a desejar em alguns quesitos.

\subsection{Moodle Palhoça Bilingue e trabalhos relacionados}

O Instituto Federal de Santa Catarina (IFSC) Campus Palhoça Bilíngue é um precursor e inovador ao criar e projetar um ambiente virtual de aprendizagem com a finalidade de atender a especificidade dos surdos, nas modalidades presencial e a distância. Esse ambiente tem estudos baseados na proposta do ambiente virtual de aprendizagem Moobi - EGC da Universidade Federal de Santa Catarina (UFSC).

Todavia, este artigo aborda mais especificamente público surdo e uma proposta de modificação que favorece a implementação de uma página inicial de cursos desenvolvido em um AVEA (Moodle) de forma a melhorar a interface e usabilidade. Ao pesquisar arcabouços teóricos, verificou-se que são escassos os trabalhos que contemplam o tema de ambientes virtuais de aprendizagem acessíveis aos surdos. Em relação à integração de surdos e ouvintes, Trindade (2013), apresenta um framework conceitual para o design de ambientes colaborativos inclusivos para surdos e não-surdos. A autora aponta ainda para a necessidade de desenvolvimento de ferramentas de comunicação que estejam em conformidade com a modalidade de comunicação dos surdos.

\section{Revisão bibliográfica}

Quanto à perspectiva do autor escolhido para análise da página inicial dos cursos do AVM Moodle Palhoça Bilíngue, Zimmerman diz a interatividade tem o conceito de interativa, mutuamente ativa, atingindo sobre ou
Realização:
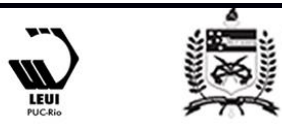


\section{$16^{\circ}$ \\ ERGODESIGN USIHC CINAHPA}

influenciando uns aos outros, permitindo um fluxo bidirecional de informações, formando assim a questão de que as informações apresentadas dos cursos estão apresentadas de forma desordenada. Assim sendo, ao acessar o ambiente AVAM o usuário tem muitas informações relacionadas na tela, algo que não permite uma escolha direta e sem complicações, pois tem de ficar procurando o curso na lista apresentada. Ainda nesse sentido Zimmerman afirma que existem 4 modos de interação:

$\checkmark$ Modo 1: interatividade cognitiva; ou a participação interpretativa de um texto.

$\checkmark$ Modo 2: interatividade funcional; ou a participação utilitária com um texto.

$\checkmark$ Modo 3: interatividade explícita; ou participação com as escolhas e procedimentos concebidos em um texto.

$\checkmark \quad$ Modo 4: Meta-interatividade ou participação cultural com um texto.

\section{Objeto de analise}

O objeto escolhido para análise é a página inicial de cursos do AVM - Campus Palhoça Bilíngue. Esse ambiente busca ser adaptado para pessoas surdas com conteúdo em língua de sinais, assim demonstra-se primeiramente a página de login conforme (figura 1).

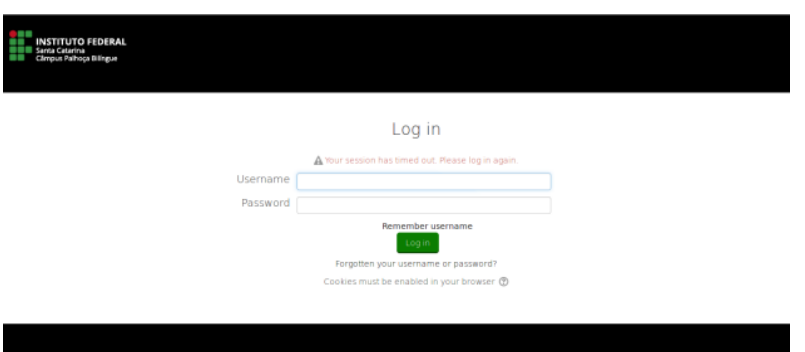

Figura 1: página de login.

Entretanto, as adaptações para os usuários surdos ainda não foram realizadas na página inicial de cursos (figura 2), em que, não há presença da língua de sinais, ou um ambiente preparado visualmente. $16^{\circ}$ Ergodesign - Congresso Internacional de Ergonomia e Usabilidade de Interfaces Humano Tecnológica: Produto, Informações Ambientes Construídos e Transporte

$16^{\circ}$ USIHC - Congresso Internacional de Ergonomia e Usabilidade de Interfaces Humano Computador

CINAHPA | 2017 - Congresso Internacional de Ambientes Hipermídia para Aprendizagem.



Figura 2: página inicial de cursos.

\section{Método}

Este estudo tem a característica de pesquisa teórico-empírica, em que, busca-se descobrir novos conhecimentos sobre o processo de usabilidade e interação de pessoas surdas em uma página de cursos de um AVM bilíngue. Sobre os objetivos da pesquisa, será do tipo descritiva e exploratória, uma vez que será explorada a realidade empírica dos sujeitos surdos em busca de conhecimento para relatar posteriormente. Segundo Gil (2008) "descreve-se o objeto do estudo, com a máxima exatidão possível os fatos e fenômenos" e "explora-se a realidade em busca de conhecimento".

A abordagem escolhida é qualitativa e os procedimentos técnicos são do tipo bibliográfico, uma vez que se utilizou além das pesquisas em livros, artigos, bancos de teses, a lente de Eric Zimmerman para decompor o objeto de estudo e abordar as considerações do autor em relação à página de cursos proposta. No contexto do AVAM, o modo de interatividade selecionado para análise é o modo 3: interatividade explícita, pois o usuário deve ler a tela com os cursos apresentados e participar ativamente através do clique para selecionar uma categoria ou subcategoria de cursos para acessar suas atividades.

A construção do protótipo para apresentação aos usuários para avaliação foi feita em uma máquina virtual na plataforma Linux - Mint. O software necessário para tanto foi o Xampp, conhecido como Lampp no caso das ferramentas gratuitas que é um gerenciador de serviços, a fim de, dar suporte aos recursos necessários para execução de um servidor fictício rodando um AVM para testes, além do Apache, MySQL, FileZilla, Mercury e 


\section{$16^{\circ}$ \\ ERGODESIGN USIHC CINAHPA}

$16^{\circ}$ Ergodesign - Congresso Internacional de Ergonomia e Usabilidade de Interfaces Humano Tecnológica: Produto, Informações Ambientes Construídos e Transporte

$16^{\circ}$ USIHC - Congresso Internacional de Ergonomia e Usabilidade de Interfaces Humano Computador

CINAHPA | 2017 - Congresso Internacional de Ambientes Hipermídia para Aprendizagem.
Tomcat. No servidor referido foram instaladas além da versão Moodle 3.0.1, o plugin do tema Adaptable. Foram criados cursos fictícios e alteradas as configurações de apresentação da tela inicial dos cursos em Marketing Blocks na guia de administração do site.

Dessa forma, será realizado um ensaio de interação na página de cursos do AVM - Campus Palhoça

Bilíngue do Instituto Federal de Educação, Ciência

e Tecnologia de Santa Catarina. Krug (2010) indica que ao menos um usuário para avaliar a interação de um determinado ambiente é suficiente para encontrar tantos problemas de usabilidade quanto usando mais participantes do teste. Assim, foram selecionados quatro usuários que possuem ensino médio completo, ou formados em nível superior e que sejam pessoas surdas.

\section{Resultados}

No ano de 2012, o AVM do Campus Palhoça Bilíngue foi projetado e implementado sem nenhuma adaptação para o público surdo (Libras/Português). Esse ambiente atendia principalmente aos professores e técnicos que visavam estudar a estrutura do AVM para cursos ofertados posteriormente. Em 2014, algumas adaptações foram realizadas para proporcionar uma página de login para que as pessoas surdas pudessem ter acesso ao AVM de forma simplificada conforme demonstrado na figura 1.

$\mathrm{O}$ projeto contou com uma equipe interdisciplinar, uma web designer, um professor programador, um professor analista de sistemas, um professor surdo, tradutores intérpretes e assistentes de edição. A interface desenvolvida foi elaborada de modo qualitativo, ou seja, a partir de reuniões e a partir da experiência com a equipe e das observações e opiniões dos professores surdos. O tema utilizado até então no AVM é o Melbourn disponível em (https://moodle.org/plugins/theme_melbourne), em que sua página de login foi alterada, mas não suas páginas internas. Como o tema Melbourn não permite muitas alterações no layout em 2016 o tema Adaptable foi instalado para prototipação do AVM com o propósito de adquirir maior flexibilidade nos ajustes visuais.
No ano de 2016 foram executados testes de inspeção e usabilidade para comparação dos dois temas, que até o presente momento não foram avaliados pela equipe administradora do AVM. Espera-se que esses resultados possam apontar uma contribuição na área de Design de interface e tecnologias acessíveis, indicando possíveis recomendações para a interface bilíngue do AVM. A figura 3 refere-se à tela de cursos do tema melbourn atualmente instalado.

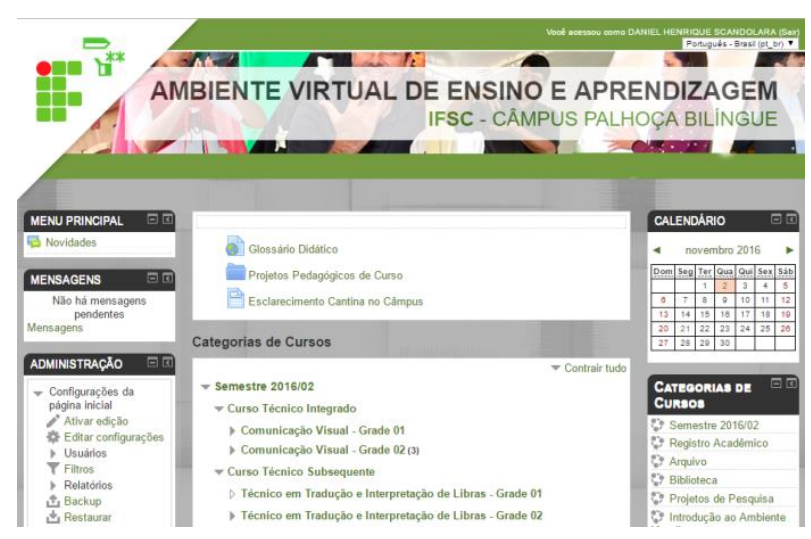

Figura 3: tema melbourn.

Nessa tela não existem opções visuais ou língua de sinais que auxiliem o público surdo. Os menus e sub menus tanto na parte esquerda ou na parte direita da página são itens que ainda não sofreram adaptações para a versão mais nova do ambiente. Os menus aqui são em formato de tópicos. $\mathrm{O}$ centro da página é composto pela lista de cursos, conforme demonstra a figura 2; página essa atualizada conforme surge a nova inserção de cursos.

Com os recursos de servidor elencados anteriormente e rodando, foi possível criar um protótipo de lista de cursos em forma visual conforme a figura 4 .

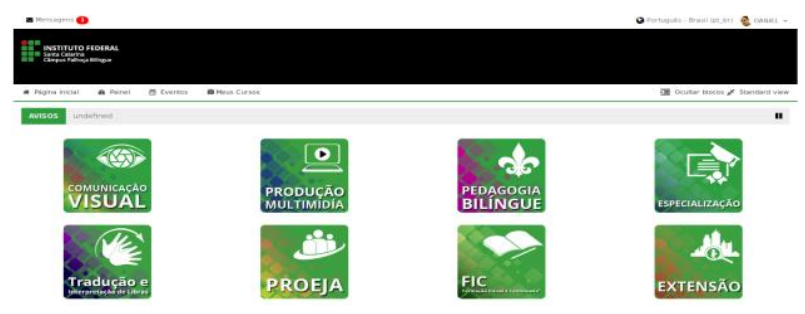

Figura 4: tema adaptable.
Realização:
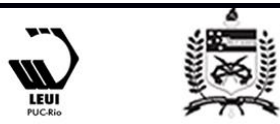


\section{$16^{\circ}$ \\ ERGODESIGN USIHC CINAHPA}

Ao elaborar o ensaio de interação e usabilidade, foram convidados quatro alunos surdos, três estudantes do ensino superior do IFSC e um estudante externo. A pesquisa foi elaborada em língua de sinais, executada no laboratório de informática do campus Palhoça Bilíngue, utilizando a gravação de tela com o software Kazam da plataforma Linux - mint e com a gravação da face do usuário através da câmera webcam utilizando o software Cheese também da plataforma Linux. Os participantes foram convidados e de forma voluntária assinaram um termo de consentimento e livre esclarecimento, conforme consta a Resolução $\mathrm{n}^{\circ} 466$ e suas complementares de 12 de dezembro de 2012 do Concelho Nacional de Saúde.

A seleção dos 4 participantes ocorreu inicialmente a partir de um questionário inicial a fim de avaliar o perfil desses voluntários. Foram feitas perguntas sobre o uso prévio de um AVM bilíngue, domínio da Língua Portuguesa e sobre o conhecimento de outros Ambientes Virtuais Bilíngues, vide a Tabela 1.

\begin{tabular}{|c|c|c|c|}
\hline Voluntário & $\begin{array}{c}\text { Conheciment } \\
\text { o Português }\end{array}$ & $\begin{array}{c}\text { Conheciment } \\
\text { o AVM } \\
\text { Palhoça } \\
\text { Bilíngue }\end{array}$ & $\begin{array}{c}\text { Conhece } \\
\text { outros } \\
\text { AVM } \\
\text { Bilíngues }\end{array}$ \\
\hline V1 & $\begin{array}{c}\text { Compreende } \\
\text { mal. }\end{array}$ & $\begin{array}{c}\text { Conhece, é } \\
\text { usuário. }\end{array}$ & $\begin{array}{c}\text { Não } \\
\text { conhece. }\end{array}$ \\
\hline V2 & $\begin{array}{c}\text { Lê bem, } \\
\text { escreve pouco. }\end{array}$ & $\begin{array}{c}\text { Conhece, é } \\
\text { usuário. }\end{array}$ & $\begin{array}{c}\text { Não } \\
\text { conhece. }\end{array}$ \\
\hline V3 & $\begin{array}{c}\text { Razoável, Lê } \\
\text { mais ou } \\
\text { menos. }\end{array}$ & $\begin{array}{c}\text { Conhece, é } \\
\text { usuário. }\end{array}$ & $\begin{array}{c}\text { Não } \\
\text { conhece. }\end{array}$ \\
& $\begin{array}{c}\text { Lê e escreve } \\
\text { razoavelmente } \\
\text { V4 }\end{array}$ & $\begin{array}{c}\text { Conhece, não } \\
\text { é usuário. }\end{array}$ & $\begin{array}{c}\text { AVMhece o } \\
\text { AVM } \\
\text { Moobi. }\end{array}$ \\
\hline
\end{tabular}

Tabela 1: Entrevista inicial dos participantes. Fonte: os autores.

Para a interação com o AVM antigo e o protótipo, foram disponibilizadas duas máquinas ao usuário, uma com o ambiente AVM (melbourn) antigo aberto, e outra com o protótipo do AVM (adaptable). Pediu-se aos voluntários que realizassem duas tarefas em cada ambiente, que consiste em: procurar o curso FIC - Formação $16^{\circ}$ Ergodesign - Congresso Internacional de Ergonomia e Usabilidade de Interfaces Humano Tecnológica: Produto, Informações Ambientes Construídos e Transporte

$16^{\circ}$ USIHC - Congresso Internacional de Ergonomia e Usabilidade de Interfaces Humano Computador

CINAHPA | 2017 - Congresso Internacional de Ambientes Hipermídia para Aprendizagem.

inicial e continuada; realizar o acesso ao curso selecionado.

Estas buscas estão relacionadas aos cursos acessados diariamente, por alunos dos cursos do Campus Palhoça Bilíngue. No entanto, cabe ressaltar que dos voluntários selecionados, 3 são alunos do curso Superior Multimídia do próprio Campus, e dessa forma, conhecem alguns dos cursos que estão dispostos na tela de categorias de cursos, por esse motivo, os pesquisadores utilizaram a estratégia ao escolher cursos que geralmente os alunos não estão habituados a acessar.

A interação dos voluntários foi observada pelos pesquisadores, o tempo total de interação foi contabilizado conforme Tabela 2.

\begin{tabular}{|c|c|c|c|c|}
\hline $\begin{array}{c}\text { Voluntári } \\
\text { o }\end{array}$ & $\begin{array}{c}\text { Ambient } \\
\text { e } \\
\text { Melbour } \\
\mathbf{n}\end{array}$ & $\begin{array}{c}\text { Ambiente } \\
\text { Adaptabl } \\
\mathbf{e}\end{array}$ & $\begin{array}{c}\text { Tarefa 1: } \\
\text { encontra } \\
\mathbf{r} \text { a } \\
\text { categoria } \\
\text { curso } \\
\text { FIC }\end{array}$ & $\begin{array}{c}\text { Tarefa 2: } \\
\text { Acessar } \\
\text { o curso }\end{array}$ \\
\hline V1 & 3 min. & 2 min. & $\begin{array}{c}\text { Encontro } \\
\text { u }\end{array}$ & Acessou \\
\hline V2 & $\begin{array}{c}\text { Não } \\
\text { encontrou }\end{array}$ & 3 min. & $\begin{array}{c}\text { Encontro } \\
\text { u }\end{array}$ & Acessou \\
\hline V3 & 4 min. & 3 min. & $\begin{array}{c}\text { Encontro } \\
\mathrm{u}\end{array}$ & Acessou \\
\hline V4 & 1 min. & 30 seg. & $\begin{array}{c}\text { Encontro } \\
\mathrm{u}\end{array}$ & Acessou \\
\hline
\end{tabular}

Tabela 2: Resultados das tarefas de interação. Fonte: os autores.

Após a interação, uma entrevista foi aplicada com algumas perguntas sobre a experiência dos voluntários quanto à interação, guiando uma conversa livre de forma individual. As questões abordadas são facilidade de uso das duas interfaces, se o formato visual das duas interfaces está de fácil entendimento e alguma sugestão de melhoria frente à especificidade da pessoa surda. Os resultados estão na Tabela 3.

\begin{tabular}{|c|c|c|c|}
\hline Voluntário & $\begin{array}{c}\text { Facilidade } \\
\text { de uso } \\
\text { Melbourn }\end{array}$ & $\begin{array}{c}\text { Facilidade } \\
\text { de uso } \\
\text { Adaptable }\end{array}$ & Melhorias \\
\hline
\end{tabular}

Realização:




$16^{\circ}$ USIHC - Congresso Internacional de Ergonomia e Usabilidade de Interfaces Humano Computador

\begin{tabular}{|c|c|c|c|}
\hline V1 & Médio & Bom & $\begin{array}{c}\text { Aumentar a } \\
\text { resolução das } \\
\text { imagens das } \\
\text { categorias de } \\
\text { cursos. }\end{array}$ \\
\hline V2 & Muito Ruim & Bom & $\begin{array}{c}\text { Uso de vídeo em } \\
\text { língua de sinais. }\end{array}$ \\
\hline V3 & Ruim & Bom & Nenhuma. \\
\hline V4 & Bom & Ótimo & $\begin{array}{c}\text { Ao passar o mouse } \\
\text { na imagem poderia } \\
\text { apresentar um } \\
\text { vídeo em libras. }\end{array}$ \\
\hline
\end{tabular}

Tabela 3: Respostas da entrevista sobre experiência de interação. Fonte: os autores.

\section{Análise e Síntese de Estudo}

Uma das principais vantagens de se realizar um ensaio de interação com usuários está justamente na possibilidade dos pesquisadores de observar os comportamentos dos usuários, sobre suas perspectivas de erros e acertos, eficácia na realização das tarefas propostas, satisfação ou insatisfação durante o uso e a interação, além da vantagem da conversa face a face com o usuário.

Sobre os objetivos desse trabalho, a principal questão é que Eric Zimmerman aponta que uma das interatividades possíveis é interatividade explícita; ou participação com as escolhas e procedimentos concebidos em um texto, ou seja, a partir do tema usado atualmente Melbourn, partese para a busca de um tema visual para os sujeitos surdos, pois a interação dessas pessoas por ser visual, não anula a escrita portuguesa, mas em muitos momentos força uma adaptação, por esse motivo, acredita-se que o tema Adaptable vai de encontro ao argumento do autor, mas com a ressalva da interação através do texto e imagem. Ao observar a interação dos usuários surdos percebe-se o uso do português, mas com certa dificuldade, justamente pelo fato da língua materna ser a língua de sinais. Entretanto a interação ocorre por meio de texto no AVM, uma vez que os cursos elencados e suas categorias estão em português.

A satisfação dos usuários surdos no AVM prototipado (Adaptable) foi positiva, pois apesar das dificuldades com a língua portuguesa, pôde de forma visual atribuir algum valor de significado para a determinada imagem. Apesar de não terem contato em sua maioria com outros AVM, foi positivo o pedido de língua de sinais no ambiente, mesmo que para trabalhos futuros. A satisfação do AVM (Melbourn) foi considerada negativa, uma vez que um dos usuários por não ler bem o português não conseguiu encontrar a categoria de curso solicitada, além da demora dos outros usuários para executar a tarefa solicitada.

A prototipação serviu para verificar que quando o projeto for implementado é necessário pensar nas imagens das categorias de cursos que serão escolhidas, considerando as referências digitais de uso desse público, utilizando a imagem como metáfora bem definida e alinhada ao curso que pertence, pois o entendimento da pessoa surda como revela a pesquisa é mais rápida ao utilizar imagens nesse sentido. Além do mais, com o ensaio de interação foi possível colaborar com o avanço do AVM do Campus Palhoça Bilíngue, reforçando a importância do uso de recursos visuais e substituição do uso do uso de textos longos para as categorias de cursos.

\section{Conclusão}

Até o presente momento, o AVM - Palhoça Bilíngue está sendo adequado para atender um público bilíngue e a tela apresentada para a nova interface está em fase de testes para ser integrada ao ambiente. As alterações necessárias devem ser feitas por uma equipe multidisciplinar, composta de pessoas surdas e ouvintes.

O trabalho aqui apresentado abordou, segundo a teoria de Zimmerman, o conceito de interação através de textos e fez a relação com a interação visual para pessoas surdas.

Os resultados obtidos serão utilizados como suporte para novas pesquisas, a fim de, proporcionar a adaptação de novas páginas do AVM.

Verificou-se em relação às telas apresentadas, que é necessário efetuar a instalação de plugins e 


\section{$16^{\circ}$ \\ ERGODESIGN USIHC CINAHPA}

também da gerencia dos mesmos para que haja compatibilidade com a versão 3.0.1 do Moodle da plataforma selecionada.

Com o estudo realizado, observou-se que as tecnologias auxiliam e facilitam a acessibilidade das pessoas surdas que vivem em comunidades surdas procurando ser inseridas e que essas ferramentas corroboram na comunicação dessas pessoas por meio de suas diferenças. Entretanto é necessário ampliar as pesquisas nessa área em relação à interação, usabilidade e acessibilidade, talvez focando também no quesito de tecnologias assistivas.

Com base nas entrevistas e na literatura apontada sobre a cultura surda é visível à importância da primeira língua (libras), ou de evidências visuais nas interfaces bilíngues. No entanto, somente com pesquisas teóricas não é alcançado tal entendimento sobre a necessidade do público surdo. Assim, ressalta-se a importância de ensaios de interação e testes de usabilidade com pessoas surdas.

Qualquer ensaio ou teste de usabilidade deve ser feito por profissionais da área, preferencialmente dominantes da língua de sinais e inclusos na comunidade surda, justamente pela compreensão dessas necessidades específicas e pala melhor aceitação do público pesquisado.

Observa-se que para elaboração de um projeto orientado a pessoas surdas, é preciso que seja feita a inserção do público durante o seu desenvolvimento e constantes testes de melhoria para resultados satisfatórios. Além desse quesito, futuras pesquisas, podem ser feitas a partir do pedido dos usuários de vídeos explicativos para as imagens apontadas no protótipo; uma vez que pesquisas na área apontam para soluções linguísticas e da cultura surda, mas nesse quesito ainda são insuficientes na área de cognição e entendimento da informação pelo usuário surdo, que é de fato essencial para acesso à informação em interfaces bilíngues. $16^{\circ}$ Ergodesign - Congresso Internacional de Ergonomia e Usabilidade de Interfaces Humano Tecnológica: Produto, Informações Ambientes Construídos e Transporte

$16^{\circ}$ USIHC - Congresso Internacional de Ergonomia e Usabilidade de Interfaces Humano Computador

CINAHPA | 2017 - Congresso Internacional de Ambientes Hipermídia para Aprendizagem.

\section{Referências Bibliográficas}

FAJARDO, I.; VIGO, M.; SALMERÓN, L. Technology for supporting web informaiton search and learning in Sign Language. Interacting with Computers. v. 21, n. 4, p. 243-256, ago 2009.

FLOR, C.; VANZIN, T. AVEAs e CoPs acessíveis para surdos sob a ótica da Teoria da Cognição Situada. In: Hipermídia e interdisciplinaridade na geração de conhecimento. São Paulo: Pimenta Cultural, 2015.

FLOR, C.; VANZIN, T.; ULBRICHT, V. Recomendações da WCAG 2.0 (2008) e a acessibilidade de surdos em conteúdos da Web. In: Revista Brasileira de Educação Especial. Vol. 19 n². Marília. Jun/2013.

GESSER, Audrei. Libras? Que língua é essa? Crenças e preconceitos em torno da língua de sinais e da realidade surda. São Paulo: Parábola Editorial, 2009.

GIL, Antonio Carlos. Métodos e Técnicas de Pesquisa Social. 6.ed. São Paulo: Atlas, 2008.

GOLDFELD, M. A criança surda: linguagem e cognição numa perspectiva sociointeracionista. 2. ed. São Paulo: Plexus. 2002.

KELLY, B. et al. Accessibility 2.0: People, Policies and Processes. In: Proceedings of the 2007. International Cross-disciplinary Conference on Web Accessibility, W4A. Proceedings... New York, USA: ACM Press, p. 138-147.

KRUG, Steve. Não me faça pensar!: Uma abordagem de bom senso à usabilidade na web. 2. ed. Rio de Janeiro: Alta Books, 2010.

PIVETTA, E. M.; SAITO, D. S.; ALMEIDA, A. M. P.;ULBRICHT, V. R. Contribuições para o design de interface de um Ambiente Virtual de Ensino Aprendizagem acessível a surdos.

InfoDesign - Revista Brasileira de Design da Informação, v. 10, n. 2, p. 193-206. 2013.

PIVETTA, E. M. et al. Otimização do Moodle
Realização:

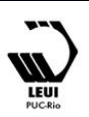




\section{$16^{\circ}$ \\ ERGODESIGN USIHC CINAHPA}

para dar suporte a Comunidades de Prática acessíveis a surdos e ouvintes. In: XIX

Conferência Internacional sobre Informática na Educação. Anais eletrônico.... Fortaleza, 2014b.

PREECE, Jennifer; ROGERS, Yvonne; SHARP, Helen. Design de Interação: além da interação Homem-Computador. $1^{a}$ Edição. Bookman Companhia, ed, 2005.

QUADROS, R. M. de. (org). Estudos Surdos III. Série pesquisas. Petrópolis, RJ: AraraAzul, 2008.

SÁ, N. L. Cultura, poder e educação de surdos. São Paulo: Paulinas, 2006.

THATCHER, J. et al. Constructing Accessible Web Sites. [S.1.]: Glasshaus, 2002.

TRINDADE, D. F. G. InCoP: um framework conceitual para o design de ambientes colaborativos inclusivos para surdos e não surdos de cultivo de comunidades de prática. Tese (Doutorado em Informática) - Programa de Pós-Graduação em Informática do Setor de Ciências Exatas da Universidade Federal do Paraná. 168f. Curitiba, 2013.

WAI. Web Accessibility Initiative. Disponível em: <http://www.w3.org/WAI/>, acesso em novembro de 2016.

W3C. ACCESSIBILITY. 2016. Disponível em: https://www.w3.org/standards/webdesign/accessibi lity. Acesso em: nov. 2016.

W3CGT. GT Acessibilidade. Disponível <http://www.w3c.br/GT/GrupoAcessibilidade\#w3c _inicio_conteudo>. Acesso Novembro de 2016.

\section{Agradecimentos}

Agradeço ao Instituto Federal de Ciência, Educação e Tecnologia de Santa Catarina -Campus Palhoça Bilíngue, pela oportunidade de realizar trabalhos como esse, pesquisando pessoas surdas e suas comunidades, com a fim de tentar auxiliar no seu desenvolvimento humano. $16^{\circ}$ Ergodesign - Congresso Internacional de Ergonomia e Usabilidade de Interfaces Humano Tecnológica: Produto, Informações Ambientes Construídos e Transporte

$16^{\circ}$ USIHC - Congresso Internacional de Ergonomia e Usabilidade de Interfaces Humano Computador

CINAHPA | 2017 - Congresso Internacional de Ambientes Hipermídia para Aprendizagem. 